\title{
COMORBIDITIES ARE FREQUENT IN PATIENTS WITH GASTROESOPHAGEAL REFLUX DISEASE IN A TERTIARY HEALTH CARE HOSPITAL
}

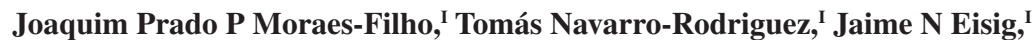

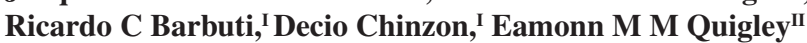

doi: $10.1590 / \mathrm{S} 1807-59322009000800013$

Moraes-Filho JPP, Navarro-Rodriguez T, Eisig JN, Barbuti RC, Chinzon D, Quigley EMM. Comorbidities are frequent in patients with gastroesophageal reflux disease in a tertiary health care hospital. Clinics. 2009;64(8):785-90.

INTRODUCTION: Several aspects of gastroesophageal reflux disease (GERD) have been studied, but the frequency of comorbidities is not yet fully understood.

OBJECTIVES: To study the prevalence of GERD comorbidities in a tertiary care hospital.

METHODS: We prospectively studied 670 consecutive adult patients from the outpatient department of our facility. A diagnosis was established using clinical, endoscopic and/or pHmetry-related findings. Each patient's medical file was reviewed with respect to the presence of other medical conditions and diagnoses.

RESULTS: Of the 670 patients, 459 (68.6\%) were female, and the mean age was 55.94 (17-80 years). We registered 316 patients (47.1\%) with the erosive form of GERD and 354 patients (52.9\%) with the non-erosive form. A total of 1,664 instances of comorbidities were recorded in 586 patients (87.5\%), with the most common being arterial hypertension (21\%), hypercholesterolemia (9\%), obesity (9\%), type II diabetes mellitus (5\%) and depression (4\%). Two or more comorbidities were present in 437 individuals $(64.8 \%)$. The occurrence of comorbidities increased with age and was higher in patients with the non-erosive form of GERD. CONCLUSIONS: In a tertiary referral population, comorbidities were very common, and these may have worsened the already impaired health-related quality of life of these patients. Clinicians caring for GERD patients in this setting must be aware of the likelihood and nature of comorbid disorders and their impact on disease presentation and patient management.

KEYWORDS: Heartburn; Regurgitation; GERD comorbidities; Esophagitis; Esophagus.

\section{INTRODUCTION}

Gastroesophageal reflux disease (GERD) is a very common and costly disorder. The majority of epidemiological studies have based their prevalence estimates on symptoms of heartburn and acid regurgitation, the cardinal symptoms of GERD, which have been reported to occur on a daily basis by $10 \%$ of the adult population in the United States ${ }^{1}$ and $7.3 \%$ in Brazil. ${ }^{2}$

\footnotetext{
${ }^{\text {I }}$ Department of Gastroenterology, Faculdade de Medicina da Universidade de São Paulo - São Paulo/SP, Brazil

II Alimentary Pharmabiotic Centre, Department of Medicine, National University of Ireland - Cork, Ireland Email: joaquim.prado@uol.com.br Tel: 55113085.3495

Received for publication on May 23, 2009

Accepted for publication on May 25, 2009
}

Many aspects of the physiopathology, diagnosis and treatment of GERD have been reviewed in detail ${ }^{3-5}$ and are relatively well known. Despite the advances in our understanding of the mechanisms of this disease, however, some important areas still remain incompletely understood, such as the prevalence and nature of comorbid disorders.

The objective of this study was to investigate the point prevalence of comorbid disorders in GERD and to assess their connection with age, gender, smoking habits and the clinical presentation of the disease (i.e., non-erosive reflux disease (NERD) vs. erosive GERD) in São Paulo, Brazil.

\section{MATERIALS AND METHODS}

A total of 670 prospective, consecutive adult patients with GERD who had been referred to the outpatient clinic of 
the Esophageal Diseases Sector of the Hospital das Clínicas of the University of São Paulo, a tertiary medical referral center, between September 2006 and December 2007 were enrolled.

The diagnosis of GERD was established on the basis of the cardinal symptoms, namely heartburn and acid regurgitation, occurring two or more times a week, with or without other symptoms, for at least 8 weeks. ${ }^{6,9}$

The Los Angeles endoscopic grading system for esophagitis severity ${ }^{8}$ was used for the endoscopic diagnosis of erosive esophagitis. NERD was diagnosed by the presence of troublesome reflux-associated symptoms and the absence of mucosal breaks at endoscopy ${ }^{7}$, in addition to 24-hour ambulatory pH-metry in the context of acid reflux. ${ }^{10}$

During the medical consultation, an extensive review of the patient's medical file was carried out, including documentation of all previous medical consultations involving different hospital services. During this review, all established diagnoses and prescribed treatments, as well as the results of any related investigations were recorded.

All comorbidities (CMs) were diagnosed according to established criteria. ${ }^{11,12}$ All data were recorded in the patient's report forms, which also included detailed information regarding the diagnosis and treatment of GERD. The results were stored in a database.

Patients were excluded if they had previously undergone gastrointestinal surgery, or if they suffered from Barrett's esophagus or other complications as evidenced during upper endoscopy. Women were required to be non-pregnant, nonlactating and on a medically acceptable form of birth control.

The study was approved by the Institutional Ethics Committee of the Hospital das Clinicas of the University of São Paulo School of Medicine (Cappesq).

A descriptive analysis was used to document the demographic and clinical data related to the patient cohort. To test for age-related statistical differences between the genders, a Student's $t$-test was used. Comparisons of the proportions among groups with regard to gender were evaluated using a binomial test, with a null hypothesis of $50 \%$ for each sex. A $p$ value of $<0.05$ was considered statistically significant. Statistical software R version 2.6.2 for windows (R Foundation for Statistical Computing, USA) was used for data processing and analyses.

\section{RESULTS}

The duration of GERD history among the 670 patients ranged from 8 weeks to 20 years (mean: 9.2 years). In total, we studied $211(31.4 \%)$ males and $459(68.6 \%)$ females; of these, $586(87.5 \%)$ had documented comorbidities, and 84 (12.5\%) did not.

Of the patients with CMs, $423(72.1 \%)$ were female and $163(27.9 \%)$ were male $(\mathrm{p}<0.0001)$. Of those without CMs, 48 (57.2\%) were male and 36 (42.8\%) were female $(\mathrm{p}=0.2301)($ Table 1$)$.

Table 1 - Presence or absence of comorbidities in relation to gender in GERD patients

\begin{tabular}{lccc}
\hline GERD & Females & Males & $P$ \\
\hline With CMs & 423 & 163 & $<0.0001$ \\
$586(87.5 \%)$ & $(72.18 \%)$ & $(27.81 \%)$ & \\
\hline Without CMs & 36 & 48 & 0.2301 \\
$84(12.5 \%)$ & $(42.86 \%)$ & $(57.14 \%)$ & \\
\hline Total & 459 & 211 & $<0.0001$ \\
670 & $(68.6 \%)$ & $(31.4 \%)$ & \\
\hline
\end{tabular}

At endoscopy, 316 patients presented erosive esophagitis (47.1\%) and $354(52.9 \%)$ did not.

Of the 316 patients with erosive esophagitis, 202 (63.9\%) were female and $114(36.1 \%)$ were male $(\mathrm{p}<0.0001)$. Of the 354 patients with non-erosive reflux disease, 257 (72.6\%) were female and $97(27.4 \%)$ were male $(\mathrm{p}<0.0001)$ (Table 2$)$.

Ages in the studied population ranged from 18 to 80 years, with a mean of 55.94 years (CI 95\%: 54.93; 56.96). The mean ages for males and females were 55.81 (CI 95\%:53.75; 57.87) and 56.0 (CI 95\%:54.87; 57.12) years, respectively. There were no statistical differences between genders with respect to age $(\mathrm{p}=0.8770)$.

Table 2 - Erosive GERD and NERD in relation to gender

\begin{tabular}{lccccccc}
\hline & \multicolumn{3}{c}{ Female } & & Male & P \\
\cline { 2 - 7 } & $\begin{array}{c}\text { CMs } \\
\text { present }\end{array}$ & $\begin{array}{c}\text { CMs } \\
\text { absent }\end{array}$ & Total & $\begin{array}{c}\text { CMs } \\
\text { present }\end{array}$ & $\begin{array}{c}\text { CMs } \\
\text { absent }\end{array}$ & Total \\
\hline Erosive GERD & 188 & 14 & 202 & 94 & 20 & 114 & $<0.0001$ \\
$316(47.1 \%)$ & $(93 \%)$ & $(7 \%)$ & $(100 \%)$ & $(82 \%)$ & $(18 \%)$ & $(100 \%)$ & 97 \\
\hline NERD & 235 & 22 & 257 & 69 & 28 & $(100 \%)$ & 211 \\
$354(52.9 \%)$ & $(91 \%)$ & $(9 \%)$ & $(100 \%)$ & $(71 \%)$ & $(29 \%)$ & 48 & $<0.0001$ \\
\hline Total & 423 & 36 & 459 & 163 & & & \\
$(670)$ & & & & & & & \\
\hline
\end{tabular}


A total of 1,664 instances of comorbidities among 586 patients $(87.5 \%)$ were identified. The ten most common comorbidities, which accounted for 1,099 occurrences (66.0\% of the total), corresponding to 509 patients $(75.9 \%$ of the total), are shown in Table 3.

A higher frequency of comorbidities occurred in the age range of 61 to 70 years, with 354 instances $(21.2 \%$ of the total occurrences), and in the age range of 51 to 60 years, with 336 instances $(20.1 \%$ of the total occurrences). The occurrence rate of the ten most prevalent CMs according to age range is shown in Table 4.

The numbers of patients by age range were: $18-20$ years, 1 ; 21-30 years, 22(3\%); 31-40 years, 59 (9\%); 41-50 years, 141 (21\%); 51-60 years, 189 (28\%); 61-70 years, $163(24 \%)$;

Table 3 - The ten most prevalent comorbidities in GERD patients

\begin{tabular}{lcc}
\hline Comorbidities & Occurrences & \% total Comorbidities \\
\hline Arterial Hypertension & 344 & 20.6 \\
Hypercholesterolemia & 158 & 9.5 \\
Obesity & 158 & 9.5 \\
Type II Diabetes mel- & 82 & 4.9 \\
litus & & \\
Depression & 74 & 4.4 \\
Arthritis & 62 & 3.7 \\
Osteoporosis & 59 & 3.5 \\
Asthma & 56 & 3.3 \\
Constipation & 54 & 3.2 \\
Allergic Rhinitis & 52 & 3.1 \\
\hline
\end{tabular}

and 71-80 years, 93 (14\%)

As seen from Table 5, the occurrence of CMs was significantly higher in patients with NERD ( $p=0.0014)$. Furthermore, in patients with erosive disease most comorbidities were associated with patients suffering from milder grades of esophagitis (i.e., Los Angeles grades A and $\mathrm{B})(\mathrm{p}<0.0001)$. Comorbidities among patients with the aforementioned grades accounted for $92.14 \%$ (CI95\%: $89.32 \% ; 94.28 \%$ ) of the total number of comorbidities associated with erosive GERD.

\section{DISCUSSION}

To our knowledge, very few original papers have analyzed the prevalence of CMs in GERD, an acid-related disorder that develops when the reflux of gastric contents induces troublesome symptoms, with or without esophageal mucosal damage and/or complications ${ }^{7}$. GERD may present with a broad spectrum of symptoms, but the cardinal manifestations are heartburn and acid regurgitation. In our study, we considered these adequate for the preliminary diagnosis of GERD. Complications of the disease, including Barrett's esoophagus, stenosis and ulcers, are often associated with other clinical manifestations and, as such, were excluded from the present study. As expected, a majority of the patients (53\%) presented with the nonerosive form of the disease. ${ }^{13}$

Although this study was conducted in a tertiary care hospital where CMs are expected, the occurrence rate of more of $80 \%$ is quite impressive. Several factors may contribute to the high prevalence of comorbidities

Table 4 - Most prevalent comorbidities in GERD sufferers according to age range

\begin{tabular}{|c|c|c|c|c|c|c|c|c|}
\hline \multirow[t]{2}{*}{ Comorbidity } & \multicolumn{8}{|c|}{ Age range } \\
\hline & $18-20$ & $21-30$ & $31-40$ & $41-50$ & $51-60$ & $61-70$ & $71-80$ & $\begin{array}{c}\text { Total } \\
\text { occurrences } \\
\text { (\% total) }\end{array}$ \\
\hline Hypertension & - & 1 & $9(15 \%)$ & $51(36 \%)$ & $98(52 \%)$ & $115(71 \%)$ & $70(75 \%)$ & $344(20.6 \%)$ \\
\hline Hypercholesterolemia & - & $2(9 \%)$ & $5(8 \%)$ & $23(16 \%)$ & $44(23 \%)$ & $58(36 \%)$ & $26(28 \%)$ & $158(9.5 \%)$ \\
\hline Obesity & - & $4(18 \%)$ & $11(19 \%)$ & $35(25 \%)$ & $51(27 \%)$ & $42(26 \%)$ & $15(16 \%)$ & $158(9.5 \%)$ \\
\hline Type II diabetes mellitus & - & 0 & 1 & $13(9 \%)$ & $20(11 \%)$ & $26(16 \%)$ & $22(24 \%)$ & $82(4.9 \%)$ \\
\hline Depression & - & 1 & $4(7 \%)$ & $18(13 \%)$ & $26(14 \%)$ & $15(9 \%)$ & $10(11 \%)$ & $74(4.4 \%)$ \\
\hline Arthritis & - & 1 & $2(3 \%)$ & $6(4 \%)$ & $20(11 \%)$ & $17(10 \%)$ & $16(17 \%)$ & $62(3.7 \%)$ \\
\hline Osteoporosis & - & - & - & $2(1 \%)$ & $13(7 \%)$ & $28(17 \%)$ & $16(17 \%)$ & $59(3.5 \%)$ \\
\hline Asthma & 1 & 1 & $3(5 \%)$ & $18(13 \%)$ & $14(7 \%)$ & $14(9 \%)$ & $5(5 \%)$ & $56(3.3 \%)$ \\
\hline Constipation & - & $2(9 \%)$ & $7(12 \%)$ & $13(9 \%)$ & $11(6 \%)$ & $13(8 \%)$ & $8(9 \%)$ & $54(3.2 \%)$ \\
\hline Allergic Rhinitis & - & 1 & $8(14 \%)$ & $11(8 \%)$ & $20(11 \%)$ & $8(5 \%)$ & $4(4 \%)$ & $52(3.1 \%)$ \\
\hline Total occurrences & 1 & 13 & 50 & 190 & 317 & 336 & 192 & 1099 \\
\hline
\end{tabular}


Table 5 - Ten most frequent comorbidities according to GERD endoscopic Los Angeles grade and NERD

\begin{tabular}{|c|c|c|c|c|c|c|}
\hline \multirow[t]{2}{*}{ Comorbidities } & \multicolumn{6}{|c|}{ GERD } \\
\hline & NERD & LA - Grade A & LA - grade B & LA - grade C & LA - grade D & $\begin{array}{c}\text { Number of Occurrences } \\
\text { (\% of total) }\end{array}$ \\
\hline Hypertension & $193(29 \%)$ & $101(15 \%)$ & $39(6 \%)$ & $9(1 \%)$ & 2 & $344(20.6 \%)$ \\
\hline Hypercholesterolemia & $84(13 \%)$ & $47(7 \%)$ & $22(3 \%)$ & $5(1 \%)$ & - & $158(9.5 \%)$ \\
\hline Obesity & $81(12 \%)$ & $42(6 \%)$ & $25(4 \%)$ & $9(1 \%)$ & 1 & $158(9.5 \%)$ \\
\hline Type II diabetes mellitus & $43(6 \%)$ & $28(4 \%)$ & $7(1 \%)$ & 3 & 1 & $82(4.9 \%)$ \\
\hline Depression & $40(6 \%)$ & $23(3 \%)$ & $10(1 \%)$ & 1 & - & $74(4.4 \%)$ \\
\hline Arthritis & $38(6 \%)$ & $13(2 \%)$ & $9(1 \%)$ & 2 & - & $62(3.7 \%)$ \\
\hline Osteoporosis & $36(5 \%)$ & $16(2 \%)$ & $5(! \%)$ & 2 & - & $59(3.5 \%)$ \\
\hline Asthma & $29(4 \%)$ & $17(3 \%)$ & $7(1 \%)$ & 2 & 1 & $56(3.3 \%)$ \\
\hline Constipation & $32(5 \%)$ & $18(3 \%)$ & $4(1 \%)$ & - & - & $54(3.2 \%)$ \\
\hline Allergic Rhinitis & $27(4 \%)$ & $15(2 \%)$ & $9(1 \%)$ & 1 & - & $52(3.1 \%)$ \\
\hline Number of occurrences ( $\%$ of total) & $603(53.0 \%)$ & $320(19.2 \%)$ & $137(8.2 \%)$ & $34(2.0 \%)$ & $5(0.3 \%)$ & 1,099 \\
\hline
\end{tabular}

observed in our series, including the fact that the study was carried out in a tertiary care hospital that receives patient referrals from primary and secondary care hospitals, as well as from healthcare centers in the city of São Paulo. As a consequence, our sample is probably biased towards individuals with more symptomatic, complicated and nonresponsive disease profiles. Furthermore, since this hospital treats a full range of medical disorders - again, on a referral basis - individuals with other medical conditions are more likely to be admitted. We emphasize, however, that our goal was not to define the relative prevalence of comorbid disorders among GERD patients and control subjects in the community, but rather to document the range of conditions that may accompany GERD in a referral hospital population. We also wished to identify factors that may contribute to their occurrence. This is not an epidemiological study, and we do not mean to imply that it is such a study.

In reality, this is a transverse, point-prevalence study in a tertiary referral population. There is some evidence, however, to suggest that the distribution and prevalence of comorbidities are representative of the general population. For instance, systemic arterial hypertension, which is known to affect 20 to $30 \%$ of the general population, ${ }^{14,15}$ was present in this series in $29 \%$ of all patients with NERD and in $20.6 \%$ of the entire GERD population studied. The same is true for the prevalence of type II diabetes mellitus, which is present in around $8 \%$ of the Brazilian population ${ }^{16}$ and in $6 \%$ and $4.9 \%$ (NERD and GERD, respectively) of the present cohort.

Obesity, which is a risk factor for GERD, has recently reached epidemic proportions, with a prevalence of $30 \%$ worldwide. ${ }^{17,18}$ Obesity was observed in $9.5 \%$ of our patients, and a similar percentage suffered from hypercholesterolemia. It is noteworthy that, together with diabetes and arterial hypertension, obesity and hypercholesterolemia constitute important risk factors for coronary heart disease ${ }^{19}$, the symptoms of which may mimic GERD and contribute to considerable diagnostic confusion. It is also important to point out that these diseases were the four most prevalent comorbidities in our study, both in isolation and in association with others. Although we do not have any data regarding serum triglyceride levels or measurements of abdominal circumference, it is possible that many of our patients were suffering from metabolic syndrome. ${ }^{20}$

Somewhat surprisingly, comorbidities were more prevalent in patients with NERD than in those with erosive disease, with a notable trend towards fewer comorbidities as the grade of esophagitis increased. Although NERD should be regarded as a real component within the GERD spectrum, ${ }^{21}$ it behaves differently with regard to the response to treatment with proton-pump inhibitors ${ }^{22}$ and demonstrates a more homogeneous acid distribution along the esophagus. ${ }^{23}$ Our findings provide further evidence for NERD being a somewhat distinctive subgroup of GERD.

Depression affects an average of $16 \%$ of the general population at some point during adult life ${ }^{24}$ and was present in $4.4 \%$ of our patients, which was somewhat lower than the expected prevalence. This may be due to the nature of our protocol, a point-prevalence study, which does not accurately capture past or future episodes. Additionally, despite its clinical importance, depression is still under-diagnosed (which may also have been a problem with the present series) due to several factors, including the minimization of symptoms and the stigma related to psychiatric disease.

It has been shown that the health-related quality of 
life (HRQoL) of patients with GERD may be seriously impaired. ${ }^{25,26}$ It is possible that the presence of comorbidities, in addition to the esophageal disease itself, also contributes to impaired quality of life in these cases. Instead of simply targeting the esophageal symptoms in such cases, a more comprehensive approach is required, which also encompasses the comorbid conditions.

Finally, an appreciation of the prevalence and nature of comorbidities should assist clinicians in identifying better therapeutic approaches for these patients. This should include consideration of the possible interactions with drugs used in the treatment of the comorbidities and of GERD, including calcium channel blockers, betaadrenergic antagonists, non-steroidal anti-inflammatory agents (NSAID's), anti-diabetic agents, sibutramine, tricyclic antidepressants, etc.
In conclusion, in a hospital with a tertiary referral population, comorbidities of GERD were very common. Such conditions may contribute to the already impaired health-related quality of life of these patients. Our findings must be studied in other settings before any generalizations can be made, but clinicians caring for GERD patients in this setting must be aware of the likelihood and nature of comorbid disorders and their impact on disease presentation and patient management.

\section{ACKNOWLEDGEMENTS}

This work was supported by an unrestricted grant from Nykomed Pharma, Brazil. We would like to thank Mr. Demerson A. Polli for his statistical guidance.

\section{REFERENCES}

1. Locke GR, Talley NJ, Fett SL, Zinsmeister AR, Melton LJ, 3rd et al. Prevalence and clinical spectrum of gastroesophageal reflux: a population based study in Omsted County, Minnesota. Gastroenterology.1997;112:1448-56.

2. Moraes-Filho JPP, Chinzon D, Eisig JN, Hashimoto CL, Zaterka S. Prevalence of heartburn and gastroesophageal reflux disease in the urban Brazilian population. Arq Gastroenterol. 2005;42:122-7.

3. Dent J. Review article: from 1906 to 2006 - a century of major evolution of understanding of gastro-oesophageal reflux disease. Aliment Pharmacol Ther. 2006;24:1269-81.

4. Sifrim D, Castell D, Dent J, Kahrilas PJ. Gastro-oesophageal monitoring: review and consensus report on detection and definitions of acid, nonacid, and gas reflux. Gut. 2004;53:1024-31.

5. Wolfe M, Lowe R. Investing in the Future of GERD. J Clin Gastroenterol. 2007;41 (suppl 2):S209-16.

6. Klauser AG, Schindlbeck NE, Muller-Lissner AS. Symptoms in gastrooesophageal reflux disease. Lancet.1990;335:205-8.

7. Vakil N, van Zanten S V, Kahrilas P, Dent J, Jones R. The Montreal definition and classification of gastroesophageal reflux disease: A global evidence-based consensus. Amer J Gastroenterol.2006;101:1900-20.

8. Lundell LR, Dent J, Bennett JR, Blum AL, Armstrong D, Galmiche JP, et al. Endoscopic assessment of oesophagitis: clinical and functional corrrelates and further validation of the Los Angeles classification. Gut.1999;45:172-80

9. Moraes-Filho JPP, Cecconello I, Gama-Rodrigues JJ, Castro LP, Henry MA, Meneghelli U, et al. Brazilian consensus on gastroesophageal reflux disease: proposals for assessment, classification, and management. Amer J Gastroenterol.2002;97:241-8.

10. De Meester TR, Wang C, Wernly JA, Pellegrini CA, Little AG, Klementschitsch W, et al. Technique, indications, and clinical use of 24 hours esophageal pH monitoring. J Thorac Cardiovasc Surg. 1980;79:656-70.
11. Goldman L, Bennett MDJC, editors. Cecil Textbook of Medicine. 21st ed. Philadelphia: Saunders; 2000.

12. Kasper DL, Braunwald E, Hauser S, editors. Harrison's Principles of Internal Medicine. 16th ed. Philadelphia: Mc GrawHill; 2005.

13. Ronkainen J, Aro P, Storskrubb T, Lind T, Bolling-Sternevald E, Junghard $\mathrm{O}$, et al. Gastro-esophageal reflux symptoms and health related quality of life in the adult general population-the Kalixanda study. Aliment Pharmacol Ther. 2006;23:1725-33.

14. Fuchs FD, Moreira LB, Moraes RS, Bredemeier, M, Cardozo, S. Prevalence of systemic arterial hypertension and associated risk factors in the Porto Alegre metropolitan area. Arq Bras Cardiol. 1994;63:473-9.

15. Hyman DJ, Pavlik VN. Characteristics of patients with uncontrolled hypertension in the United States. New Engl J Med. 2001;345:479-86.

16. Malerbi DA, Franco LJ. Multicenter study of the prevalence od diabetes mellitus and impaired glucose tolerance in the urban Brazilian population aged 30-69 years. The Brazilian Cooperative Group on the Sudy of Diabetes Prevalence. Diabetes Care. 1992;15:1509-16.

17. El-Serag HB, Graham DY, Satia, JA, Rabeneck L. Obesity is an independent risk factor for GERD symptoms and erosive esophagitis. Am J Gastroenterol. 2005; 100:1243-50.

18. CDC. State-specific prevalence of obesity among adults-United States, 2005. MMWR.2006;55:985-8.

19. Malik S, Wong ND, Franklin SS, Kamath TV, L'Italien GJ, Pio JR, et al. Impact of the metabolic syndrome on mortality from coronary heart disease, cardiovascular disease, and all causes in United States adults. Circulation. 2004;110:1245-50.

20. Executive Summary of the Third report of the National Cholesterol Education Program (NCEP) Expert Panel on detection, evaluation, and treatment of high blood cholesterol in adults (adult treatment panel III). JAMA. 2001;285:2486-97. 
21. Quigley EMM. NERD, GERD and Beyond. A consideration of the expanding spectrum of gastroesophageal reflux disease. J Clin Gastroenterol. 2007;41:S175-80.

22. Dean BB, Gano AD, Knight K, Ofman JJ, Fass R. Effectiveness of proton pump inhibitors in non erosive reflux disease. Clin Gastroenterol Hepatol. 2004;2:656-64.

23. Dickman R, Bautista JM, Wai-Man W, Bhatt R,Beeler JN, Malagon BS, et al. Comparison of esophageal acid exposure distribution along the esophagus among the different gastroesophageal reflux disease (GERD) Groups. Am J Gastroenterol. 2006;101:2463-9.
24. Waraich P, Goldner EM, Somers JM, Hsu L1. Prevalence and incidence studies of mood disorders; a systematic review of the literature. Can J Psychiatry. 2004; 49:124-38.

25. Madisch A, Kulich KR, Malfertheiner P, Ziegler K, Bayerdörffer E, Miehlke S, et al. Impact of reflux disease on general and disease-related quality of life-evidence from a recent comparative methodological study in Germany. Z Gastroenterol. 2003;41:1137-43.

26. Cury MS, Ferrari A, Ciconelli R, Ferraz MB, Moraes-Filho JPP. Evaluation health-related quality of life in gastroesophageal reflux disease patients before and after the treatment with pantoprazole. Dis Esophagus. 2006;19:289-93. 